\title{
Child Health Policies from the Lens of Equality in Iran: A Qualitative Study
}

\author{
Narges Rouhi ${ }^{1}$, Hasan Jafari ${ }^{2}$, Fatemeh Setoodehzadeh ${ }^{3}$ and Mostafa Amini-Rarani (iD ${ }^{4,}$ \\ ${ }^{1}$ Disaster Risk Management Office, Deputy for Health Ministry of Health, Tehran, Iran \\ ${ }^{2}$ Department of Health Care Management, Health Policy and Management Research Center, School of Public Health, Shahid Sadoughi University of Medical Sciences, Yazd, \\ Iran \\ ${ }^{3}$ Health Promotion Research Center, Zahedan University of Medical Sciences, Zahedan, Iran \\ ${ }^{4}$ Social Determinants of Health Research Center, Isfahan University of Medical Sciences, Isfahan, Iran \\ "Corresponding author: School of Management and Medical Information Sciences, Isfahan University of Medical Sciences, Hezar-Jerib Ave., Isfahan, Iran. Email: \\ m.amini@mng.mui.ac.ir
}

Received 2018 December 26; Revised 2019 May 25; Accepted 2019 July 11.

\section{Abstract}

Background: While child health inequality is emerging as one of the main issues in child health policies, the identification of factors which intensify this kind of inequality via the qualitative method has attracted little attention.

Objectives: The aim of the study was to identify the equality issues in child health policies in Iran.

Methods: Data were collected using semi-structured interviews with 19 key informants from July 2015 to December 2016. A purposeful and snowball sampling method was used to select participants. Using MAXQDA 12, the recorded interviews were transcribed verbatim and thematically analyzed.

Results: Four themes and fifteen subthemes were extracted in terms of equality issues in child health policies, including: (1) implementation of child health policies (rational distribution, addressing rural and underserved regions and full access), (2) strengths of child health policies (comprehensive and integrated healthcare, educating mothers, and targeting programs based on the burden of disease), (3) challenges of child health policies (health information system and faults in data registration, complications in child health education, traditional beliefs and believing in fate, and ignoring social determinants of health), and (4) priority actions (improving fathers' health literacy, promoting socio-economic and cultural status, enhancing health information system, suburban and rural areas, and regional planning).

Conclusions: Reliance on comprehensive and integrated care, health education and targeting program and diminishing challenges and weaknesses can be considered as a policy guide aiming to reduce inequality in child health outcomes. Also, besides addressing executive issues, challenges, and strengths; priorities as policy entry points should be considered simultaneously.

Keywords: Child Health, Health Policy, Inequality, Qualitative Research

\section{Background}

Health inequalities are among prominent issues which have increasingly been put on policy agenda $(1,2)$ and discussed in publications $(3,4)$. The socioeconomic gaps in child health are not a simple matter of inequality but a type of inequity (5). Thus, research in this field still has a long way to go (6). It is implied that child health concerns should be taken into account in the post-millennium development goals (MDGs) period. Consequently, the reduction of inequality among and inside countries has been adopted as the tenth goal of the sustainable development goals (SDGs) in 2015 (7). Several studies have been conducted accordingly $(3,8,9)$. Nevertheless, from the health policy perspective, current child health interven- tions are usually implemented without regard for equality (10). Despite numerous works measuring inequality in child health outcomes $(11,12)$, progress toward socioeconomic inequality reduction has been hindered, especially in low- and middle-income countries, due to a lack of documentation and narrow understanding of socioeconomic inequality trends in child health indices (13). Unfortunately, benefits from the total improvement in child health is generally not distributed proportionately across different socioeconomic groups (11), and it is less clear which policies can diminish child health inequalities (14). In other words, substantial evidence exists in child health inequality reduction at the globe and also in Iran (15), but we need to learn how child health policies might ensure equality aspects of child health outcomes. 
From an equality perspective, solely focusing on national rates could be misleading (16), i.e. it is possible that improvements in child health outcomes occurred in the better-off population and children belonging to the worseoff groups lagged behind.

Some quantitative studies in Iran measured socioeconomic inequality in child health outcomes (i.e., child health mortality) and decomposed it into related determinants using representative national demographic and health survey (DHS) data $(11,17)$.

\section{Objectives}

The current qualitative study, for the first time in Iran, adds descriptions and explanations of the equality aspects of child health policies from the viewpoint of key informants and experts and provides recommendations for future equality-based child health policy.

\section{Methods}

\subsection{Setting}

An interpretative, qualitative study design was used to identify the challenges, strengths, and priorities of child health inequality. We sought the perspectives of experts and key informants in the child health area and child health policy at macro- (Ministry of Health and Medical Education (MoHME)), meso- (medical universities), and micro- (healthcare network) levels in Iran. The data were collected from September 2015 to June 2016.

\subsection{Sampling}

We employed the purposive sampling method to identify interviewees. In addition, the snowball sampling method was used to create a related human network, reach more interviewees, and complete the list of participants. Eligible interviewees were key informants and experts related to child health policy making and delivering child healthcare. We excluded key informants and experts if they had an experience $<5$ years and/or cancelled the interview meeting more than five times. Totally, 5, 7 and 7 experts at the macro, meso and micro levels were interviewed, respectively. Table 1 shows the characteristics of the interviewees.

\subsection{Data Collection and Analysis}

Face-to-face semi-structured interviews were carried out by a member of the study team (MAR). The interviews were conducted in the interviewees' office or any location suggested by them. All interviews were recorded with the permission of interviewees and then transcribed verbatim as soon as possible. Each interview lasted 25 - 50 min. Formal consent was given before proceeding with the interviews. Data saturation was reached after 19 interviews. At saturation point new data were no longer illuminating the themes and interview comments and patterns began to repeat and little new material was generated. At nineteenth interview our major analytic categories have been saturated and seems little point in continuing and so it would be appropriate to bring data collection to a halt. Besides the interviews, some child health programs, including the Integrated Management of Child Illness, Well-Baby Care, 1-59-Month Child Mortality Surveillance System, Integrated Mothers' Healthcare, and Baby-Friendly Hospital Program were reviewed to further understand the child health policy content in Iran. The thematic analysis approach was applied to analyze the data using the MAXQDA 12 software. The step-by-step guide proposed by Braun and Clarke was applied including familiarization with data, generating initial codes, searching for themes, reviewing themes, defining and naming themes, and producing the report (18).

\subsection{Ethical Consideration}

In addition to giving formal consent, all interviewees were informed of the study before the interview meetings. Participation in the present study was voluntary and all interviewees were permitted to quit or stop the interview during the interview process. Confidentiality of information was assured.

\subsection{Quality Assurance}

Credibility, transferability, dependability, and confirmability of our findings were confirmed. Prolonged engagement (about10 months) and participant checks (some transcribed interviews were reviewed via the interviewees) were adopted to improve the credibility. The purposive sampling method and detailed descriptions avoided unclear statements, thereby increasing the transferability of the data. Furthermore, we cross-checked the data and recruited external reviewers to confirm the dependability and confirmability of results.

\section{Results}

Table 1 shows the characteristics of the interviewees. Based on participants' ideas, four themes and 15 subthemes were identified from interviews (Table 2). Each theme and its sub-themes are explained in more detail below. 


\begin{tabular}{|c|c|c|c|c|}
\hline & Organization & Level & Sex & Experience \\
\hline $\mathbf{1}$ & MoHME- Public Health Deputy & macro & Male & 15 \\
\hline 2 & MoHME- Public Health Deputy & macro & Female & 13 \\
\hline 3 & MoHME- Child Health Office & macro & Male & 20 \\
\hline 4 & MoHME- Child Health Office & macro & Male & 18 \\
\hline 5 & MoHME- Child Health Office & macro & Female & 10 \\
\hline 6 & Medical universities & meso & Female & 12 \\
\hline 7 & Medical universities & meso & Female & 15 \\
\hline 8 & Medical universities & meso & Male & 9 \\
\hline 9 & Medical universities & meso & Female & 8 \\
\hline 10 & Medical universities & meso & Male & 13 \\
\hline 11 & Medical universities & meso & Male & 16 \\
\hline 12 & Medical universities & meso & Male & 19 \\
\hline 13 & Healthcare network & micro & Female & 14 \\
\hline 14 & Healthcare network & micro & Female & 15 \\
\hline 15 & Healthcare network & micro & Male & 7 \\
\hline 16 & Healthcare network & micro & Male & 12 \\
\hline 17 & Healthcare network & micro & Female & 6 \\
\hline 18 & Healthcare network & micro & Female & 5 \\
\hline 19 & Healthcare network & micro & Male & 17 \\
\hline
\end{tabular}

\subsection{Implementation}

\subsubsection{Rational Distribution}

Participants stated that if we are concerned about equality in child health, we should rationalize the distribution of child healthcare by focusing primarily on the expansion of primary health care and development of a network system. I.e. child health polices in Iran were equitable in implementation because they rationally were distributed based on PHC principles:

"In health policy debates, we believe that our approach has been equitable because of running primary health care (PHC) centers... Equality is one of the PHC principles, and the Iranian government, specially the Ministry of Health and Medical Education, makes enormous effort and allocates resources to develop and implement PHC across all regions in Iran" (Participant 1).

\subsubsection{Rural and Underserved Regions}

Based on the findings, health programs for children in Iran have been implemented actively in rural areas, in addition to improving and providing services in suburban and remote areas. For equal distribution and retention of specialist and sub-specialist workers in underserved areas and villages, some incentive policies were employed on the basis of compulsory commitment period. In this regard, one of the policymakers told us that:

"We provide financial incentives for pediatrics if they spend commitment periods in the disadvantaged areas and remote villages of some provinces." (Participant 2).

\subsubsection{Full Access}

One of the key concepts of universal coverage is the commitment to provide access to health services for all population groups and equity in access to health services. Most respondents declared that child healthcare services, regardless of children's socio-economic status, are accessible for almost all Iranian children.

"In all cities and villages, all neonates, infants, and underfive children in all socio-economic groups, whether poor or rich, residing in rural or urban areas, can go to health house or health centers and receive all maternal and child healthcare services." (Participant 3).

\subsection{Strengths of Child Health Policies to Tackle Inequality}

\subsubsection{Comprehensive and Integrated Healthcare}

Most key informants confirmed that child health policies are developed based on an integrated healthcare approach. Therefore, systematically, children are considered 
Table 2. The Thematic Analysis Explaining the Theme and Subtheme of Equality in Child Health in Iran

\begin{tabular}{|c|c|c|}
\hline Row & Theme & Subtheme \\
\hline \multirow{3}{*}{$\mathbf{1}$} & \multirow{3}{*}{ Implementation } & Rational distribution \\
\hline & & $\begin{array}{l}\text { Addressing rural and underserved } \\
\text { regions }\end{array}$ \\
\hline & & Full access \\
\hline \multirow{3}{*}{2} & \multirow{3}{*}{ Strengths } & $\begin{array}{l}\text { Comprehensive and integrated } \\
\text { healthcare }\end{array}$ \\
\hline & & Educating mothers \\
\hline & & $\begin{array}{l}\text { Targeting programs based on the } \\
\text { burden of disease }\end{array}$ \\
\hline \multirow{4}{*}{3} & \multirow{4}{*}{ Challenges } & $\begin{array}{l}\text { Health information system and faults } \\
\text { in data registration }\end{array}$ \\
\hline & & $\begin{array}{l}\text { Complications in child health } \\
\text { education }\end{array}$ \\
\hline & & Traditional beliefs and believing in fate \\
\hline & & Ignoring social determinants of health \\
\hline \multirow{5}{*}{4} & \multirow{5}{*}{ Priority actions } & Improving fathers' health literacy \\
\hline & & $\begin{array}{l}\text { Promoting socio-economic and } \\
\text { cultural status }\end{array}$ \\
\hline & & Enhancing health information system \\
\hline & & Suburban and rural areas \\
\hline & & Regional planning \\
\hline
\end{tabular}

as a whole and all preventive and curative care services are provided for them. A key informant declared:

"Prevention and treatment services and complete examination and screening for children, such as examining weight, height, and head circumference; assessing nutritional and developmental status; vaccination; and giving supplement drops, are done in child healthcare." (Participant 15).

\subsubsection{Educating Mothers}

All interviewees pointed that educating mothers is one of the strengths of child health programs. In this regard, health workers in health houses and health centers have a responsibility to teach all mothers, especially illiterate and semi-literate ones, about child caring and healthy behaviors. Participants mentioned that educating mothers has had a positive effect on improving child health in all groups:

"Educating mothers have had a tremendous influence on the methods of healthy child caring and rearing" (Participant 10)

\subsubsection{Targeting Programs Based on the Burden of Disease}

In designing and setting priorities for related interventions in child health policy, the focus was on the burden of disease and epidemiological transition of diseases from communicable diseases to non-communicable diseases and injuries.

"As disease scenarios and burdens have been changed, interventions have also been changed based on epidemiological transition." (Participant 11).

\subsection{Challenges of Child Health Policies}

4.3.1. Health Information System and Faults in Data Registration

The lack of appropriate and detailed data at the level of individuals or households and even at the level of city, lack of information about household distribution within the country, unidentified socio-economic status of households, and errors in data entering and documentation are important issues in this regard. One of the interviewees at the Ministry of Health and Medical Education said:

"We have had routine data but have not made a systematic survey at the household level. Now, ifyou ask me in which socioeconomic group or socio-economic status did these registered child deaths occur, I'll tell you, 'I don't know'.” (Participant 4).

\subsubsection{Complications in Child Health Education}

Challenges regarding this sub-theme include the illiteracy or semi-literacy of mothers or the low literacy of mothers, lack of mother or family participation in child health education, absurdity of education in households with economic and criminal problems, time scarcity of health workers for education, and lack of training skills. All these challenges resulted in the low effectiveness of child health education, especially in low-income households:

"We cannot say that $98 \%$ of people are literate in Iran. It is a reality that a person studying for five grades can only meet basic needs, find an address, and count money! He/she does not understand, for example, O.R.S, blood pressure, microbe, or trauma appropriately. Indeed, we face low literacy (more intensely, low health literacy) in Iran." (Participant 12).

\subsubsection{Traditional Beliefs and Believing in Fate}

According to many interviewees, wrong traditional beliefs are another challenge in inequality in child health. Because of some common beliefs such as fatalism (health and death as part of Allah's predetermined fate), sickness and health coming from Allah, and inept protective jealousy, some families avoid visiting health centers for receiving necessary maternal and child services:

"We face wrong beliefs in some places. For example, many people say 'We can't escape disease because it is Allah's fate', 'Illness and death are in God's hand', and 'Diseases are Allah' punishment'. Surly, people who believe these statements will not seek health for themselves or their children." (Participant 9). 
Regarding inept protective jealousy, one of the healthcare network personnel said:

"Many men do not allow their wives to receive pregnancyrelated examination by gynecologists, GPs, or midwifes. They even say'I want my wife to give birth at home... It's none ofyour business. My mother gave birth at home and there was no problem. So, if Allah wishes, no problem will happen for my wife either." (Participant 17)

\subsubsection{Ignoring Social Determinants of Health}

Despite the existing evidence showing the importance of social determinants of health (SDH) in under-five mortality reduction, related programs and interventions for child health have mostly been focused on biological aspects:

"It is quite strange that even experts are unaware of SDH and do not realize the impact of SDH on health." (Participant 6).

"There is a note here. There is still some skepticism about SDH among medical experts, but the fact is that SDH can play an important role in the health and disease of people." (Participant 8).

\subsection{Priority Actions}

\subsubsection{Improving Fathers' Health Literacy}

Regardless of the necessity and importance of fathers' health literacy in maternal and child care, this issue has been overlooked in many child health policies. However, if the father has adequate health literacy, he can really invest on the health of his family and try to improve the health status of his wife and children.

"Training the fathers is also a part of the priority tasks. The father's role is very effective in willingness to pay for maternal and child health care, allowing visiting health centers, and providing psychological and emotional support during pregnancy and breastfeeding." (Participant 2).

\subsubsection{Promoting Socio-Economic and Cultural Status}

Based on the interviewees' comments, some of the most important priorities of socio-economic and cultural conditions are improving the socio-economic status of households, strengthening social protection and social security systems, addressing the cultural aspects of child health, and establishing a healthy lifestyle in children via early child development.

\subsubsection{Enhancing Health Information System}

For many of those interviewed, having detailed information at the level of city and households was one of the requirements of equality-based child health policy.
"In working on inequality, having detailed data is a key element. Without data we don't effectively act against inequality." (Participant 2).

Another key-informant told us that:

"High-quality information will help us know who gets services and who does not, who provides services, and where and when services are provided." (Participant 3).

\subsubsection{Suburban and Rural Areas}

Some interviewees acknowledged that, despite the good start of service delivery in villages and easier access in rural areas via PHC, suburban areas have been somewhat neglected.

"Now, we have 10 million marginalized people in cities that are in worse health conditions even compared to those in rural areas. We should consider the suburbs and provide active services for them if we want to achieve equality in our society." (Participant 4).

Nevertheless, rural areas still have their own problems in terms of access to health facilities and utilization of healthcare.

\subsubsection{Regional Planning}

Some believe that we should choose the best method to reduce inequality in the region according to socioeconomic and cultural characteristics, priorities, and local requirements and capabilities with regional and bottomup policy making.

"We should focus on policies in a decentralized way in which a province or city can identify its own vulnerable and disadvantaged regions and, prioritize its needs based on this knowledge, and finally implement the most effective policy." (Participant 5).

Finally, a related conceptual model for tackling child health inequality was extracted as depicted in Figure 1.

\section{Discussion}

The main aim of the present study was to find out whether child health policies in the Iran's health system have equality considerations. This section provides discussions on some highlighted results. Interviewees noted the following implemented programs that directly aim at child health: Integrated Management of Childhood Illness (IMCI), Well-Baby Program, Neonatal Health Program, Early Child Development Program, Baby-Friendly Hospitals, and 1-59-Month Child Mortality Surveillance System. They argued that since the focus of all these programs was on primary health care (PHC) approach, they indirectly affected the socioeconomic inequality in child health outcomes. This finding is consistent with the results of the 


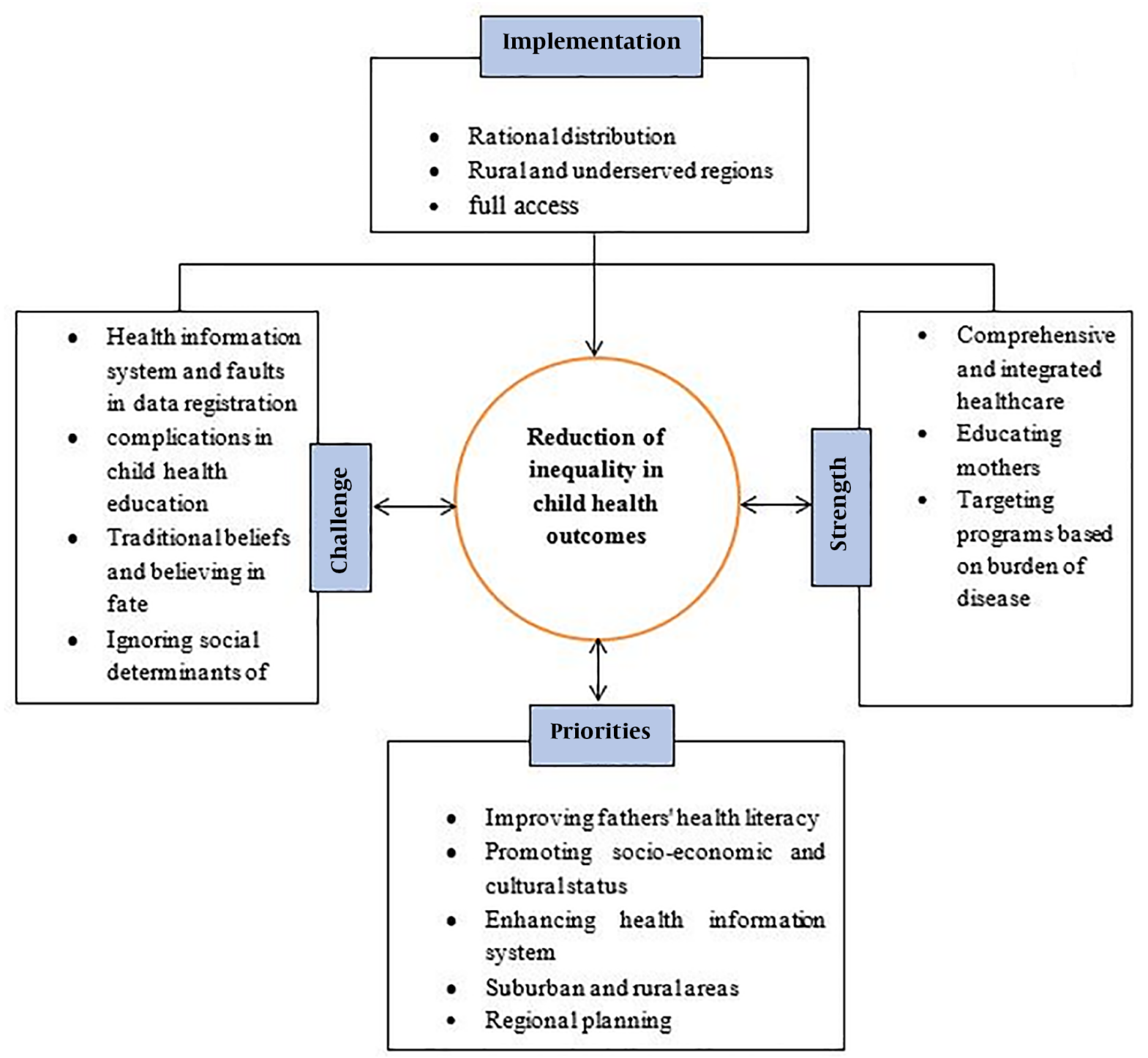

Figure 1. Conceptual model for action on child health inequality in Iran

study that has been determined the appropriate criteria for conducting and evaluating interventions related to inequality in European regions. The researchers concluded that the PHC criteria offered for development, implementation, and evaluation of intervention aiming to reduce inequality in health are useful tools for reducing health inequities throughout Europe (19).

The interviewees noted that child health policies via integrated care, addressing rural and deprived areas, focusing on health education, mortality registration, and prioritizing in terms of the burden of disease tried to tackle inequality in child health. Regarding the rational distribution of child healthcare services, the health system in
Iran has implemented a primary health care network and scaled up the network system to rationalize the distribution of services, especially in the post-revolutionary period. Meanwhile, country-wide and other national programs such as poverty alleviation in underprivileged areas, rural development, and national five-year development plans (FYDP) have been equity-oriented. Consequently, programs in the health sector also moved towards equality. Regarding the universal coverage of child healthcare, interviewees declared that one of the focal points of child health policy was providing access to preventive, therapeutic, and rehabilitation services for all children, regardless of their socioeconomic status, financial situation, or area 
of residence. Fenn et al. (20) used eight national surveys of Bangladesh, Benin, Cambodia, Eritrea, Haiti, Malawi, Nepal, and Nicaragua and showed that, in all countries (except for Haiti), more coverage in interventions (including vaccination, pre- and post-pregnancy care, and skilled birth attendance) was evident with fewer child deaths across wealth groups.

According to the interviewees, the implemented child health programs and interventions managed to reduce socioeconomic inequality through their comprehensiveness and integration, focusing mother's health education, and targeting based on the burden of disease. Integrated child health programs not only focus on child disease treatment but also provide comprehensive prevention and rehabilitation services. Health education such as oral rehydration therapy (ORT), using skilled birth attendance rather than traditional midwives, exclusive breastfeeding until six months, and keeping up-to-date the knowledge of maternal and childcare professionals regarding the local and national levels of the country, have also been used as important and effective factors in childhood disease prevention and child mortality, which is consistent with the results of Kavanagh's study (21). She noted that, the United States established children's Bureau in 1912 and assigned a national committee to promote child health and welfare, thereby making a prominent progress in this field. She also addressed the challenges and opportunities faced by maternal and child health (MCH) professionals in the US and emphasized that educated and trained $\mathrm{MCH}$ professionals will help overcome challenges and ensure the health of mothers and children nationwide. Moreover, in the case of illiterate mothers or mothers with low educational levels, child healthcare is actively followed by health workers. Therefore, education can close gap in child health by focusing on mothers belonging to lower socio-economic households or non/poorly educated mothers. All child health policies have been developed and implemented based on the main causes of death and epidemiological transition from communicable diseases to non-communicable diseases and injures.

Participants stated that one of the main challenges in child health planning toward decreasing inequalities arises from the deficit in health system information. Having information at the level of households and regions helps us to identify poor, more vulnerable, high-risk, and disadvantaged households and thus provide them with need-based services and facilities. Challenges for child health education can be found in relation to the problems of illiterate or poorly-educated people. Child health education is ineffective in these groups who mainly have financial problems. From an equality perspective, illiteracy and money shortage are well-known problems in poor households. Therefore, we do not expect health education to effectively improve child health outcomes among the poor compared to the rich. Another challenge in reducing socioeconomic inequalities in child health outcomes is false traditional beliefs which are more prevalent among poorer, less affluent, vulnerable, and more deprived and marginalized people (22). These include fatalism and false beliefs, marriage and pregnancy at a young age, family marriages, wrong beliefs about health and illnesses, the desire to have more childbirth, and so on. Therefore, issues related to traditional beliefs in disadvantaged groups are a challenge for reducing adverse outcomes of child health. Also, in some cases, due to societal pressures and social taboos associated with troubled families (such as those with addicted, HIV-positive, and prostitute member), health workers may be reluctant to communicate with them and, as a result, these families are deprived from some educational and counseling services. In many cases, the high rates of child mortality and morbidity are associated with the household's social problems. Therefore, merely focusing on medical and physical aspects of health and not paying enough attention to social determinants of health are challenges of child health inequality reduction. In the case of child health policies, since the main goal of social determinants-based programs is acting to reduce health inequalities, the failure to address social determinants in child health interventions and policies has led to an increase in child health inequality.

Improving the level of fathers' health literacy must be considered as a priority alongside improving the education of mothers and other family members (young girls and boys) in order to reduce the inequality in child health. One of the priorities highlighted by the majority of respondents in the area of literacy was the issue of low literacy among mothers that should be considered in child health policies and by health workers. The findings of the study conducted by Song and Burgard confirmed the findings of the present study (23). They showed that Chinese infants born to better educated mothers have had less mortality during 1970 - 2000 because educated mothers more actively sought prenatal care and used professional delivery assistance. Promoting socio-economic and cultural status, according to many interviewees, is a priority for improving inequality in child health outcomes. In order to improve the socioeconomic and cultural situations of Iranian households, the interviewees made the following suggestions: improving the social and economic conditions of households, strengthening social structures and the social support system for further benefiting the poor, addressing the financial and economic problems of households, creating fair employment and good work, supporting the poor through appropriate subsidy distribution, consider- 
ing cultural dimensions in child health policies, and giving every child the best start in life. These priorities are in line with those mentioned in many other studies presented in the (24).

Several experts declared that addressing suburban and rural areas in Iran is one of the main current priorities in reducing inequality in adverse child health outcomes including child mortality. The main contribution of remote and marginal areas to child mortality inequality was recognized in numerous other studies in other parts of the world, including Drabo's, which used data from 90 developed and developing countries (25), and Assan et al.'s in Indonesia (26). In Iran, Hosseinpoor et al. showed that living in rural areas is one of the most important determinants of inequality in infant mortality (17). These findings are in line with the results of decomposing the concentration index of neonatal mortality between 1995 - 2000 and 2005 - 2010 in Iran (11). Addressing regional planning was among other priorities mentioned by the interviewees to decrease inequality in child health outcomes. According to them, because socioeconomic characteristics, regional capacities, needs, and facilities differ from one place to another, and since most health inequalities are concentrated across specific socioeconomic or ethnic groups and particular areas, regional-contextual-based planning and interventions are more successful for improving inequality in child health. Moreover, these regionalized plans can be flexible at regional and local levels based on available resources, needs, and requirements. To this end, participants offered the following suggestions: decentralization in child health policy-making, particularly in deprived and vulnerable regions; empowerment of medical universities to develop programs tailored to their needs; and advocacy from/involvement of other health-related local organizations and authorities in child health policies.

\subsection{Limitations of the Study}

The main limitation of this study was conducted formal interviews with key informants. Some informants do not have enough time for interviewing. This is a common problem in qualitative data gathering. For this, interviews were conducted according to the willingness of interviewees in any place where they were located and in any time when they were scheduled. Moreover, because most of the interviewees at macro level have preoccupation during the interview, the responses maybe influenced.

\subsection{Conclusions}

According to the findings, Iran has indirect plans to reduce the socioeconomic inequality in child health outcomes. To put it more precisely, all child health policies are PHC-based, i.e. all these programs are implicitly directed to reduce socioeconomic inequality. Interviewees mentioned literacy level, socioeconomic status, and addressing rural and suburban areas as the most important and high-priority factors to reduce socioeconomic inequality in child health. In addition, regarding the priorities and influential factors, the interviewees went further and noted other factors, including cultural status, having a detailed information platform, and regional planning as effective, high-priority factors in terms of child health inequality reduction. Concerning the inequality situation in child health, policies and programs aim to reduce socioeconomic inequality in child health for all Iranian children by the rational distribution of child healthcare services and addressing rural and underserved regions. Nevertheless, these policies and programs have several weaknesses and challenges that can act as threats in tackling socioeconomic inequalities in child health. Therefore, reliance on the aforementioned strength points, improving them, and diminishing challenges and weaknesses can be considered as a policy guide aiming to reduce socioeconomic inequality in child health. Moreover, priorities as policy entry points should be taken into account besides addressing executive issues, challenges, and strengths. Based on the findings of the study, it is recommended that in the future research, child health policy analysis is done considering analysis of policy and analysis for policy approaches.

\section{Acknowledgments}

Authors wish to thank the all study participants for their kind contribution.

\section{Footnotes}

Authors' Contribution: Mostafa Amini-Rarani contributed in the conception and design of the work. Narges Rouhi drafted the manuscript. Hasan Jafari critically revised the manuscript draft. Fatemeh Setoodehzadeh commented on manuscript and revised final version. All contributed to the analysis and interpretation; all approved the final version.

Conflict of Interests: We have no conflict of interests including direct financial payment for the research or manuscript production by sponsors related child health and personal consultant for companies or other organizations with financial interests for promotion of particular child health policies or programs.

Ethical Approval: Ethical issues (Including plagiarism, informed consent, misconduct, data fabrication and/or falsification, double publication and/or submission, redundancy, etc.) have been completely observed by the authors. 
Moreover, this study received the required ethics approval from Tehran University of Medical Sciences Research Ethics Committee, Tehran, Iran with ethical code No. 136890.

Funding/Support: This study was supported in part by Tehran University of Medical Sciences.

\section{References}

1. Braveman P, Gruskin S. Defining equity in health. J Epidemiol Com munity Health. 2003;57(4):254-8. doi: 10.1136/jech.57.4.254. [PubMed: 12646539]. [PubMed Central: PMC1732430].

2. Marmot MG. Status syndrome: A challenge to medicine. JAMA. 2006;295(11):1304-7. doi: 10.1001/jama.295.11.1304. [PubMed 16537740].

3. Bailey ZD, Krieger N, Agenor M, Graves J, Linos N, Bassett MT. Structural racism and health inequities in the USA: Evidence and interventions. Lancet. 2017;389(10077):1453-63. doi: 10.1016/S01406736(17)30569-X. [PubMed: 28402827].

4. Committee on the Long-Run Macroeconomic Effects of the Aging U.S. Population-Phase II; Committee on Population; Division of Behavioral and Social Sciences and Education; Board on Mathematical Sciences and Their Applications; Division on Engineering and Physical Sciences; The National Academies of Sciences Engineering and Medicine. The growing gap in life expectancy by income: Implications for federal programs and policy responses. Washington (DC): National Academies Press (US); 2015.

5. Victora CG, Vaughan JP, Barros FC, Silva AC, Tomasi E. Explaining trends in inequities: Evidence from Brazilian child health studies. Lancet. 2000;356(9235):1093-8. doi: 10.1016/S0140-6736(00)02741-0. [PubMed: 11009159].

6. Bryce J, Victora CG, Black RE. The unfinished agenda in child survival.Lancet. 2013;382(9897):1049-59. doi:10.1016/S0140-6736(13)617535. [PubMed: 24054535].

7. United Nation. Transforming our world: The 2030 agenda for sustainable development. New York: UN; 2015.

8. McKetta S, Hatzenbuehler ML, Pratt C, Bates L, Link BG, Keyes KM. Does social selection explain the association between statelevel racial animus and racial disparities in self-rated health in the United States? Ann Epidemiol. 2017;27(8):485-492 e6. doi 10.1016/j.annepidem.2017.07.002. [PubMed: 28778656]. [PubMed Central: PMC5610069].

9. Sequist TD. Urgent action needed on health inequities among American Indians and Alaska Natives. Lancet. 2017;389(10077):1378-9. doi: 10.1016/S0140-6736(17)30883-8. [PubMed: 28402807].

10. Victora CG, Fenn B, Bryce J, Kirkwood BR. Co-coverage of preventive interventions and implications for child-survival strategies: Evidence from national surveys. Lancet. 2005;366(9495):1460-6. doi 10.1016/S0140-6736(05)67599-X. [PubMed: 16243091].

11. Amini Rarani M, Rashidian A, Khosravi A, Arab M, Abbasian E, Khedmati Morasae E. Changes in socio-economic inequality in neonatal mortality in Iran between 1995-2000 and 2005-2010: An oaxaca decomposition analysis. Int J Health Policy Manag. 2017;6(4):219-
8. doi: 10.15171/ijhpm.2016.127. [PubMed: 28812805]. [PubMed Central: PMC5384984].

12. Van Malderen C, Speybroeck N. Decomposing overall and wealthrelated inequality in under-5 mortality in three East-European countries: Albania, Armenia and Ukraine, 2007-2010. Eur J Pub Health. 2013;23(suppl_1).doi:10.1093/eurpub/ckt123.153.

13. Pradhan J, Arokiasamy P. Socio-economic inequalities in child survival in India: A decomposition analysis. Health Policy. 2010;98(23):114-20. doi:10.1016/j.healthpol.2010.05.010. [PubMed: 20576309].

14. Exworthy M, Blane D, Marmot M. Tackling health inequalities in the United Kingdom: The progress and pitfalls of policy. Health Serv Res. 2003;38(6 Pt 2):1905-21. doi:10.1111/j.1475-6773.2003.00208.x. [PubMed: 14727803]. [PubMed Central: PMC1360979].

15. Amini Rarani M, Rashidian A, Arab M, Khosravi A, Abbasian E. Measuring socioeconomic inequality changes in child mortality in Iran: Two national surveys inequality analysis. Iran J Public Health. 2018;47(9):1379-87. [PubMed: 30320013]. [PubMed Central: PMC6174055].

16. Sousa A, Hill K, Dal Poz MR. Sub-national assessment of inequality trends in neonatal and child mortality in Brazil. Int J Equity Health. 2010;9:21. doi: 10.1186/1475-9276-9-21. [PubMed: 20815875]. [PubMed Central: PMC2944212].

17. Hosseinpoor AR, Van Doorslaer E, Speybroeck N, Naghavi M, Mohammad K, Majdzadeh R, et al. Decomposing socioeconomic inequality in infant mortality in Iran. Int J Epidemiol. 2006;35(5):1211-9. doi: 10.1093/ije/dyl164. [PubMed:16987848].

18. Braun V, Clarke V. Using thematic analysis in psychology. Qual Res Psychol.2006;3(2):77-101. doi: 10.1191/1478088706qp063oa.

19. Daponte A, Bernal M, Bolivar J, Mateo I, Salmi LR, Barsanti S, et al. Criteria for implementing interventions to reduce health inequalities in primary care settings in European regions. Eur J Public Health. 2014;24(6):980-90. doi: 10.1093/eurpub/cku044. [PubMed: 24739138].

20. Fenn B, Kirkwood BR, Popatia Z, Bradley DJ. Inequities in neonatal survival interventions: Evidence from national surveys. Arch Dis Child Fetal Neonatal Ed. 2007;92(5):F361-6. doi: 10.1136/adc.2006.104836. [PubMed: 17379739]. [PubMed Central: PMC2675357].

21. Kavanagh L. Challenges and opportunities facing maternal and child health (MCH) professionals. Matern Child Health J. 2015;19(2):236-9. doi: 10.1007/s10995-014-1661-2. [PubMed: 25555383].

22. Lynam MJ, Loock C, Scott L, Khan KB. Culture, health, and inequalities: New paradigms, new practice imperatives. J Res Nurs. 2008;13(2):13848. doi: 10.1177/1744987108088639.

23. Song S, Burgard SA. Dynamics of inequality: Mother's education and infant mortality in China,1970-2001. J Health Soc Behav. 2011;52(3):34964. doi: 10.1177/0022146511410886. [PubMed: 21896686].

24. Berkman LF, Kawachi I, Glymour M. Social epidemiology. . Oxford University Press; 2014. doi: 10.1093/med/9780195377903.001.0001.

25. Drabo A. Impact of income inequality on health: Does environment quality matter? Environ Plan A Econ Space. 2011;43(1):146-65. doi: 10.1068/a43307.

26. Assan JK, Kumar M, Burman E, Assan SK, Assan N, Smith L. Health inequality in resource poor environments and the pursuit of the MDGs: Traditional versus modern healthcare in rural Indonesia. $J$ Health Manage. 2009;11(1):93-108. doi: 10.1177/097206340901100107. 